\begin{tabular}{|c|c|c|c|c|c|c|}
\hline \multirow{4}{*}{ Impact Factor: } & ISRA (India) & $=3.117$ & SIS (USA) & $=0.912$ & ICV (Poland) & $=6.630$ \\
\hline & ISI (Dubai, UAE & $=0.829$ & РИНЦ (Russia & $=\mathbf{0 . 1 5 6}$ & PIF (India) & $=1.940$ \\
\hline & GIF (Australia) & $=0.564$ & ESJI (KZ) & $=8.716$ & IBI (India) & $=4.260$ \\
\hline & JIF & $=1.500$ & SJIF (Morocco & $=5.667$ & OAJI (USA) & $=0.350$ \\
\hline
\end{tabular}

\section{SOI: $\underline{1.1 / \mathrm{TAS}}$ DOI: $\underline{10.15863 / \mathrm{TAS}}$ International Scientific Journal Theoretical \& Applied Science}

p-ISSN: 2308-4944 (print) e-ISSN: 2409-0085 (online)

Year: 2019 Issue: $04 \quad$ Volume: 72

Published: $20.04 .2019 \quad$ http://T-Science.org

SECTION 17. World history. History of science and technology.
QR - Issue

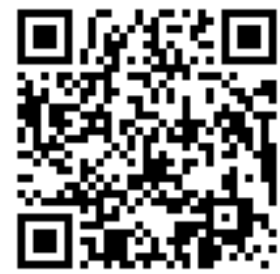

The Russian Presidential Academy of National Economy and Public Administration, Russian Federation

Timur Al'bertovich Magsumov

$\mathrm{PhD}$ in History, Associate Professor Naberezhnye Chelny State Pedagogical University, Russian Federation

International Network Center for Fundamental and Applied Research, United States of America

\title{
NABEREZHNYE CHELNY IN 1969-1985: COMMUNISTIC IDEAL AND REALITIES OF THE "CITY OF THE FUTURE"
}

\begin{abstract}
Article executed in the problem field of historical urbanistics and social history represents the first in a domestic historiography experience of judgment of a complex of the questions connected with social aspects of processes of an urbanization to Naberezhnye Chelny in the second half of the 1960th - the first half of the 1980th. The new industrial cities, having been "new details" of the engine of industrial development of the Country of Councils, showed mechanisms of the operated Soviet urbanization, contradictory processes and results of their sociocultural development. The description and the analysis of this experience opens the new research horizons of consideration of practice and semantics of the Soviet urbanization. Having been successful experience of new Soviet town planning, Boats kept also a number of problems inherent in it: the shortage of financial resources, division of powers for decision-making, extensive functionality and responsibility of the Soviet municipal government playing in comparison with the western cities, where a big role as the government tried to provide all needs of citizens, including requirements satisfied by the private sector in nonsocialist societies. Authors seek to find out balances and distortions between the purposes and the actual results of their embodiment set for new types of sotsgorod.

Key words: Urban history, Social history, Russian studies, Local history, Naberezhnye Chelny, USSR, late socialism.

Language: Russian

Citation: Kovzik, G. O., \& Magsumov, T. A. (2019). Naberezhnye Chelny in 1969-1985: communistic ideal and realities of the "city of the future". ISJ Theoretical \& Applied Science, 04 (72), 263-267.

Soi: http://s-o-i.org/1.1/TAS-04-72-28 Doi: crossef https://dx.doi.org/10.15863/TAS.2019.04.72.28

\section{НАБЕРЕЖНЫЕ ЧЕЛНЫ В 1969-1985 ГГ.: КОММУНИСТИЧЕСКИЙ ИДЕАЛ И РЕАЛИИ «ГОРОДА БУДУЩЕГО»}

Аннотация: Статья, выполненная в проблемном поле исторической урбанистики и социальной истории, представляет собой первый в отечественной историографии опыт осмысления комплекса вопросов, связанных с сочиальными аспектами процессов урбанизации в г. Набережные Челны во второй половине 1960-х - первой половине 1980-х гг. Новые индустриальные города, явивиись «новыми деталями» двигателя промышленного развития Страны Советов, продемонстрировали механизмы управляемой советской урбанизации, противоречивые процессы и результаты их сочиокультурного развития. Описание и анализ этого опыта раскрывает новые исследовательские горизонты рассмотрения практики и семантики советской урбанизации. Явившись успешным опытом нового советского градостроительства, Челны сохранили и ряд присущих ему проблем: нехватку финансовых ресурсов, разделение полномочий для принятия решений, обширный функционал и ответственность советского городского управления, играюшего, в сравнении с западными городами, куда большую роль, поскольку правительство пыталось обеспечить все потребности граждан, в том числе потребности, удовлетворяемые частным сектором в
\end{abstract}




\begin{tabular}{|c|c|c|c|c|c|c|}
\hline \multirow{4}{*}{ Impact Factor: } & ISRA (India) & $=3.117$ & SIS (USA) & $=0.912$ & ICV (Poland) & $=6.630$ \\
\hline & ISI (Dubai, UAE & $=0.829$ & РИНЦ (Russia) & $=0.156$ & PIF (India) & $=1.940$ \\
\hline & GIF (Australia) & $=0.564$ & ESJI (KZ) & $=8.716$ & IBI (India) & $=4.260$ \\
\hline & JIF & $=1.500$ & SJIF (Morocco & $=5.667$ & OAJI (USA) & $=0.350$ \\
\hline
\end{tabular}

несочиилистических обществах. Авторы стремятся выяснить балансы и перекосы между поставленными для новых типов сочгородов цеелями и фактическими результатами их воплощения.

Ключевые слова: историческая урбанистика, социальная история, русистика, краеведение, Набережные Челны, СССР, поздний соичиализм.

\section{Introduction}

Социалистический индустриальный город мечта будущего или разочарование? На протяжении всего существования Советского Союза концепция соцгорода существенно трансформировалась, не меняя своей сущности: максимальное благоустройство урбанистической зоны в духе компактности, шаговая доступность, многофункциональность архитектурных сооружений. История Набережных Челнов резко ускорилась после начала грандиозной стройки Камского автомобильного завода. В быту возникло определение «старого» и «нового» города. В течение 20 с лишним лет в Челнах активно шел процесс создания социалистического индустриального города, результаты которого до сих пор изучены не в полной мере.

10 ноября 1982 года по Стране Советов прокатилась весть о кончине Леонида Ильича Брежнева, Генерального секретаря ЦК КПСС. Человек, правивший бессменно почти 18 лет [7], ушел, оставив целую эпоху. В силу отечественной политической традиции было решено увековечить память лидера - «борца за коммунизм» - в названии крупного города. Выбор пал на Набережные Челны - город, при Леониде Ильиче ставший одним из последних «мегапроектов» социалистической экономики. 19 ноября того же 1982 года «Набережные Челны» на шесть лет становятся «Брежневым».

\section{Materials and Methods}

До первой трети XX столетия Набережные Челны - прекрасное и богатое село, затем небольшой городок с населением от 5 до 33 тыс. человек (статус города присвоен Набережным Челнам постановлением ВЦИК СССР от 10 августа 1930 г.), вплоть до принятия судьбоносного решения, превратившего город в 34-й по численности среди 1113 городов современной России (по численности населения г. Набережные Челны опережает порядка 70 столиц мира). 14 августа 1969 г. Политбюро ЦК КПСС своим постановлением определило, что именно «в Набережных Челнах Татарской АССР» будет построен комплекс автомобильных заводов для производства большегрузных автомобилей и дизельных двигателей. С этого момента город был обласкан судьбой. Ему досталась собственная отдельная страница в отечественной и мировой истории [3, С. 3-4].

Исследование идеального типа социалистического города в послевоенную эпоху следует отнести к одному из важных направлений в таких отраслях научного знания, как урбанистика, локальная и социокультурная история [9; 12]. Город Набережные Челны представляется одним из последних в мировой истории примеров города индустриального типа, с градообразующим предприятием - Камским автомобильным заводом (КамА3; ныне КАМАЗ).

Спроектированный, а не сформировавшийся в ходе естественного развития, новый город олицетворял доминировавший дискурс трансформированной концепции соцгорода об окружающем советских горожан жизненном пространстве. Микрорайонирование, шаговая доступность до объектов социально-культурного быта, таких как школы и детские сады, дома культуры и больницы, прямые, проходящие сквозь всё городское пространство проспекты и улицы, - всё это так походило на архитектонику другого послевоенного типично индустриального города Тольятти, расположенного по российским меркам не так далеко от Набережных Челнов всего в 313 км. При рассмотрении в определенных ракурсах эти «урбанистические побратимы», пожалуй, неотличимы.

Крах государственной коммунистической идеологии, демонтаж системы советов, сопутствовавший им глубокий социальноэкономический кризис повлияли на развитие индустриальных городов России в новых условиях хозяйствования [6]. Значительная их часть подверглась обструкции и деградации, но некоторые города, особенно в первое десятилетие XXI века, сконструировали новую или реструктурировали предыдущую модель дальнейшей динамики и даже успешно ее реализовали. Тем не менее, масштабный переход от широкой социальной политики государства к адресной социальной защите населения не мог не повлиять на развитие этих городов и, в особенности, на качество жизни горожан.

Практику функционирования всеохватной и массовой советской системы культуры и здравоохранения можно и нужно учитывать в выстраивании новых стратегий социальной и городской политики в настоящем. Накопленный опыт, особенно успехи, просчеты и недостатки планирования и организации социальнокультурного быта, позволит перестроить дорожную карту «плавной трансформации» городской среды на новый уровень, точнее определить ориентиры развития индустриальных городов на ближнюю и дальнюю перспективу. Широкому научному осмыслению должна 


\begin{tabular}{|c|c|c|c|c|c|c|}
\hline \multirow{4}{*}{ Impact Factor: } & ISRA (India) & $=3.117$ & SIS (USA) & $=0.912$ & ICV (Poland) & $=6.630$ \\
\hline & ISI (Dubai, UAE & $=0.829$ & РИНЦ (Russia) & $=0.156$ & PIF (India) & $=1.940$ \\
\hline & GIF (Australia) & $=0.564$ & ESJI (KZ) & $=8.716$ & IBI (India) & $=4.260$ \\
\hline & JIF & $=1.500$ & SJIF (Morocco & $=5.667$ & OAJI (USA) & $=0.350$ \\
\hline
\end{tabular}

подвергнуться цельная концепция социалистического индустриального города, с его положительными и отрицательными сторонами.

Важнейшей чертой большинства таких городов было наличие градообразующего предприятия. $\mathrm{B}$ советский период истории российские индустриальные города получали от этого феномена сильнейший импульс для собственного развития. Одним из ярких тому примеров может служить рост численности населения в Набережных Челнах с начала строительства КАМАЗа. За счёт колоссальных финансовых вливаний в городе выстраивалась совершенно новая для страны инфраструктура, не обремененная факторами изношенности и необходимостью учета социокультурных элементов при проектировании и урбанизации местной округи. Несмотря на принцип остаточности фондирования материальных средств на обеспечение социально-культурных условий жизни горожан, в целом можно говорить об успешности такой форсированной модернизации провинциального города в современный (по тем меркам, разумеется) социалистический индустриальный город. Однако в нынешних условиях этот исторический тип в целом успешного урбанистического развития с уклоном в сторону тяжелой индустрии превратился в отягчающий и сковывающий развитие социальных и экономических процессов. Сегодня моногорода в условиях новых российских реалий находятся на «особом внимании» в социально-экономической повестке властей. Программы демонополизации городской экономики и выведения ее из-под зависимости стагнирующих предприятий-гигантов свидетельствуют о желании разрешить накопленные ошибки и недочеты.

В свете вышеописанных факторов представляемое читателю исследование фокусируется на осмыслении советского опыта социокультурной политики в новых индустриальных городах на примере Набережных Челнов времен зрелого социализма. Краеведческий оттенок монографии изначально задавал авторам необходимость использования местами явной нарративности в изложении происходящих процессов в совокупности их фактографии. Это обусловлено также отсутствием введения в научный оборот обширного массива городского делопроизводства, которому авторы также были вынуждены уделить особое внимание.

За кратчайший срок провинциальный городок со своей, признаем, локальной ролью даже не в российской, а в региональной татарстанской - истории, «ворвался» в когорту экономических «столпов» советской промышленности и превратился в один из крупных индустриальных городов Советского
Союза, став своеобразным ядром одноименной полицентрической городской агломерацииконурбации. Строительство Камского автомобильного завода придало настолько сильный импульс развитию Набережных Челнов, что науке еще только предстоит колоссальная работа в изучении данного урбанистического сюжета в историческом и социальноэкономическом измерении. Город на Каме после активной фазы строительства автозавода и новой жилой части, стал историческим феноменом с типическими чертами унификации, стандартизации и массового строительства.

На историческом горизонте сверхдержавы возник новый колосс. Во многом - это итог единого и многоликого порыва в борьбе за свершения и лучший, идеальный мир десятков и сотен тысяч простых советских людей, их битвы за лучший по благоустроенности район, за лучшее социально-культурное и медицинское обслуживание, за полноценную музыкальную или художественную школу при дворе, за больший охват книжными и картинными выставками, ярмарками и выездными концертами приезжих артистов для строителей и новых горожан.

«Город «оформляет», определяет особый тип человека» [1, С. 9]. Проводниками этих побед стали тысячи работников культуры и здравоохранения, консолидированных общими идеями о лучших способах облагораживания человеческой духовности и создания максимально комфортных условий жизни советского человека в новом идеальном социалистическом городе. Допускаем, что этот, как и многие другие, примеры трудового подвига советской интеллигенции стали серьезной посылкой для включения ее в союз рабочих и крестьян как социальной основы СССР в новую Конституцию 1977 года.

Набережные Челны стал своеобразной «витриной» развитого социализма, но не для «заграницы» (хотя международные делегации приезжали для ознакомления с городом регулярно), а для «внутреннего потребителя» советского гражданина. Универсальной догмой во всех решениях и резолюциях партийных съездов послеоттепелевской поры выступало всемерное улучшение уровня жизни советских граждан. И, если возникновение на пустыре гигантского индустриального производства презентовалось как победа социализма над капитализмом, то выстраиваемая практически параллельно ему жилая инфраструктура и, с запаздыванием, инфраструктура социальная должны были стать в государственной идеологической системе реально воплощенным символом перехода к развитому социализму.

В целом, необходимо отметить схожесть процессов строительства и жизнедеятельности 


\begin{tabular}{|c|c|c|c|c|c|c|}
\hline \multirow{4}{*}{ Impact Factor: } & ISRA (India) & $=3.117$ & SIS (USA) & $=0.912$ & ICV (Poland) & $=6.630$ \\
\hline & ISI (Dubai, UAE & $=0.829$ & РИНЦ (Russia & $=0.156$ & PIF (India) & $=1.940$ \\
\hline & GIF (Australia) & $=0.564$ & ESJI (KZ) & $=8.716$ & IBI (India) & $=4.260$ \\
\hline & JIF & $=1.500$ & SJIF (Morocco & $=\mathbf{5 . 6 6 7}$ & OAJI (USA) & $=0.350$ \\
\hline
\end{tabular}

новых социалистических индустриальных городов в общесоюзной динамике. Резко ускоренное, форсированное развитие, с одной стороны, в ближайшей перспективе отчетливо улучшало уровень жизни горожан. Напротив, такие скоростные темпы роста сформировали на ближайшее и будущее время целый комплекс проблем - от нехватки работников высшей квалификации вследствие не устоявшегося образовательного кластера в городе, а также недостатка обеспеченности фондов для возведения объектов соцкультбыта, и заканчивая отягчающим фактором градообразующего предприятия-монополиста, препятствующих дальнейшему развитию города в новых исторических социально-экономических реалиях. Мрачным напоминанием о великих, но нереализованных планах стали множественные долгострои: не проложенные трамвайные линии (данный вид транспорта вплоть до принятия принципиального решения в 2015 году действовал, будучи зацикленным только на нуждах заводчан), серо-бетонные скелеты недостроенных корпусов медицинского городка, местный небоскреб-гостиница, с зияющими черными просветами вместо окон... Перечисляемый список таких объектов может быть большим. Он стал приметной чертой новых индустриальных городов позднего социализма, да и не только советских городов - чего стоит куда более печальный пример Детройта с его центромпризраком и центром-гетто. Однако к началу 2010-х годов в Набережных Челнах большинство задумок было доведено до логического завершения, что свидетельствует о начале прохождения наиболее сложной стадии урбанизма будущего индустриального города в новый, благоустроенный, ориентированный на каждого человека, а не на определенные социальные группы населения.

Специфика социокультурного состава приезжего населения, его cultural background в целом настоятельно требовал от местных властей скорейшего формирования условий для полноценного проживания в городе [10, С. 41; 5]. Ввиду того, что молодежь стала обзаводиться семьями [2], акцент ставился на создание насыщенной разноплановыми событиями культурной жизни города, а также на организацию сети учреждений культуры для будущих юных челнинцев [8]. Финансирование этой сферы шло «постольку поскольку», поэтому, не без участия местных властей, цеха и предприятия КамАЗа стали брать под патронаж музыкальные и художественные школы, выделать из своих средств деньги на приобретение инвентаря.

Схожие действия прослеживаются в городской системе здравоохранения [11]. Столкнувшись с непомерными темпами демографического подъема, а также резким ростом заболеваемости и одновременным отсутствием полноценной инфраструктуры, управленцы стремились форсировано выстроить сеть медицинских объектов: родильных домов, диспансеров, поликлиник. Не менее ответственной и неотложной параллельной задачей стало их обеспечение штатом квалифицированных медицинских кадров.

\section{Conclusion}

Стоит признать тот факт, что идеи о социалистическом типе индустриального города воплотились, и уже не исчезнут из пространственной среды Набережных Челнов. Его культурные и архитектурно-градостроительные особенности прочно вошли в городскую «конституцию», и если даже историей будет уготована судьба выхолащивания этой урбанистической концепции, то данный процесс будет продолжительным. Однако есть ли вообще необходимость полностью стирать проявления советского прошлого из города? Этот вопрос следует причислить к одному из вечных в российской истории, поскольку общество до сих пор не пришло к единому мнению и согласию в том, насколько ценны для нас культурные пласты предыдущих идеологий и поколений.

Главная задача историка - разобраться, почему так произошло. Набережным Челнам предстоит, как мы надеемся, ещё долгий исторический путь, но без понимания специфики контекста его генезиса и развития, дальнейшее продвижение будет сопряжено с риском допущения критических ошибок, способных резко ухудшить качественные параметры уровня жизни горожан. Полагаем, что в нашей монографии [4] представлен если не многоаспектный, то объективный ответ на вопрос о том, от каких основ идет в будущее Автоград на реке Каме. 


\begin{tabular}{|c|c|c|c|c|c|c|}
\hline \multirow{4}{*}{ Impact Factor: } & ISRA (India) & $=3.117$ & SIS (USA) & $=0.912$ & ICV (Poland) & $=6.630$ \\
\hline & ISI (Dubai, UAE & $=0.829$ & РИНЦ (Russia & $=\mathbf{0 . 1 5 6}$ & PIF (India) & $=1.940$ \\
\hline & GIF (Australia) & $=0.564$ & ESJI (KZ) & $=8.716$ & IBI (India) & $=4.260$ \\
\hline & JIF & $=1.500$ & SJIF (Morocco & $=5.667$ & OAJI (USA) & $=0.350$ \\
\hline
\end{tabular}

\section{References:}

1. Ageeva, E. Y. (2004). Gorod kak sotsiokul'turnoe obrazovanie [City as sociocultural education]. N.Novgorod.

2. Akhmetova, M. K., Bobkova, E. Y., Magsumov, T. A., \& Maksimov, Y. A. (2017). Ekologicheskie praktiki kak sposob interiorizatsii ekologicheskoi modeli povedeniya uchashcheisya molodezhi [Environmental practices as the means of developing ecological behavioural model in students]. Sovremennye issledovaniya sotsialnykh problem [Russian Journal of Education and Psychology], 8 (7): 330-346. DOI: $10.12731 / 2218-7405-2017-7-$ 330-346

3. Gayfutdinov, A. M., \& Magsumov, T. A. (2019). Progulki po Chelnam i Tatarstanu: uchebnoe posobie po ekskursionno-kraevedcheskoy rabote so shkol'nikami $i$ studentami [Walks across Naberezhnye Chelny and Tatarstan: the manual on excursion and local history work with school students and students]. Krasnoyarsk: Nauchnoinnovatsionnyy tsentr. http://nkras.ru/arhiv/2019/magsumov.pdf DOI: $10.12731 / 978-5-6042232-8-4$

4. Kovzik, G. O., Magsumov, T. A., Nigmatullina, M. O., \& Titova, S. V. (2019). Naberezhnye Chelny v 1969-1985 gg.: sotsial'naya istoriya modernizatsionnogo eksperimenta epokhi zrelogo sotsializma [Naberezhnye Chelny in 1969-1985: social history of a modernization experiment of an era of mature socialism]. Krasnoyarsk: Nauchno-innovatsionnyy tsentr. DOI: $\underline{10.12731 / 978-5-907208-02-5}$

5. Magsumov, T. A. (2013). Kul'turnoobrazovatel'naya sreda provintsial'nogo goroda $\mathrm{V}$ fokuse lokal'noi istorii: po stranitsam rabot sochinskikh kraevedov [The cultural and educational environment of a country town in focus of local history: according to pages of works of the Sochi local historians]. $V$ mire nauchnykh otkrytii, 11 (47): 143-149.

6. Magsumov, T. A., \& Kovzik, G. O. (2014). Gibel' imperii: regional'nyy aspekt [Death of the empire: regional aspect]. $V$ mire nauchnykh otkrytiy, 5: 12-17.

7. Magsumov, T. A., Nizamova, M. S., \& Shakirov, R. R. (2015). Istoriya Rossii: uchebnik dlya vuzov [History of Russia: Textbook for Universities]. DOI: $10.12731 /$ HR.2015.346

8. Magsumov, T. A., \& Titova, S. V. (2011). Kul'turno-obrazovatel'naya sreda Naberezhnykh Chelnov v 1973-1993 gg. v zerkale sotsial'noy infrastruktury [The cultural and educational environment of Naberezhnye Chelny in 19731993 in a mirror of social infrastructure]. Mezhdunarodnyy zhurnal eksperimental'nogo obrazovaniya, 11: 118-119.

9. Nizamova, M. S. (2015). Kraevedenie kak yavlenie $\mathrm{v}$ zhizni russkoy provintsii [Study of local lore as the phenomenon in life of the Russian province]. V mire nauchnykh otkrytiy, 5 1 (65): 321-327.

10. Magsumov, T. A., \& Kovzik, G. O. (2016). Socialist competitions in culture (on materials of Naberezhnye Chelny in 1974-1985). Gardarika, 1 (6): 41-52. DOI: $10.13187 /$ gard.2016.6.41

11. Magsumov, T. A., \& Nigmatullina, M. O. (2017). Reorganization and Expansion of the Network of Medical Institutions of Naberezhnye Chelny (the 1960th - the Beginning of the 1980th). Journal of International Network Center for Fundamental and Applied Research, 4-2 (2): 91-99. DOI: $10.13187 /$ jincfar.2017.2.91

12. Nizamova, M. S. (2017). Russian province: questions of a historiography of a sociocultural phenomenon. Journal of International Network Center for Fundamental and Applied Research, 4 (2): 100-103. 